\title{
NEOLIBERALISMO E EXPANSÃO DO AGRONEGÓCIO GLOBALIZADO NO BRASIL
}

\author{
NEOLIBERALISM AND EXPANSION OF THE GLOBALIZED AGRIBUSINESS IN BRAZIL
}

Henrique Faria dos Santos $^{\mathbf{A}}$

${ }^{\text {A }}$ Universidade Estadual de Campinas (UNICAMP), Campinas, SP, Brasil

Recebido em: 04/11/2021 | 04/01/2022～DOI: $10.12957 /$ tamoios.2022.63310

Correspondência para: Henrique Faria dos Santos (livehenriquefariasantos@hotmail.com)

\begin{abstract}
Resumo
O objetivo do presente artigo é discutir as bases de expansão e consolidação do agronegócio globalizado no território brasileiro que, na atualidade se fundamenta, em seu conteúdo político e econômico, no Neoliberalismo. Nas últimas décadas, o país vivenciou grandes transformações na atividade agropecuária em função da progressiva modernização das operações agrícolas, logísticas e de comercialização, tendo como protagonistas nesse processo a atuação estratégica do Estado e as grandes empresas nacionais e transnacionais. Várias regiões e seus respectivos municípios foram incorporados, de forma socialmente excludente e ambientalmente insustentável, à lógica de produção e exportação competitiva de commodities agrícolas para os mercados internacionais, o que tem acarretado diversas implicações socioespaciais. A superação do padrão produtivo derivado dos Complexos Agroindustriais e a constituição de uma agricultura científica globalizada trouxeram novos desafios à organização econômica e política do território, bem como situações geográficas de vulnerabilidade nas principais regiões produtivas do agronegócio.
\end{abstract}

Palavras-chave: agronegócio globalizado; neoliberalismo; território brasileiro; vulnerabilidade territorial.

\begin{abstract}
This article discusses the bases of the globalized agribusiness expansion and consolidation in Brazil, which in currently based, in its political and economic content, on Neoliberalism. In recent decades, Brazil has experienced considerable transformations in the agricultural activity due to the progressive modernization of agricultural, logistical, and marketing operations. The strategic actions of the State and of the large national and transnational companies had substantial protagonism in this process. Several regions and their respective municipalities have been incorporated, in a socially exclusive and environmentally unsustainable way, into the logic of competitive production and export of agricultural commodities to international markets, which has resulted in several socio-spatial implications. Overcoming the productive pattern derived from Agroindustrial Complexes and the establishment of a globalized scientific agriculture created new political and economic organization challenges, as well as geographical situations of vulnerability in the main productive regions of agribusiness.
\end{abstract}

Keywords: globalized agribusiness; neoliberalism, Brazilian territory; territorial vulnerability. 


\section{INTRODUÇÃO}

Nas últimas décadas, o campo brasileiro vem passando por grandes transformações socioeconômicas e ambientais, dado o conjunto de reestruturações técnicas e normativas ocorridas na agropecuária, sobretudo em lugares cuja produção é voltada predominantemente para o mercado externo. Várias regiões do país estão passando por um processo acelerado de especialização produtiva agrícola, consequentemente acompanhado de um aprofundamento da divisão territorial do trabalho, movimento que é fomentado e controlado cada vez mais por poderosas corporações nacionais, transnacionais e instituições financeiras globais, sob uma lógica de mercado marcada pela busca incessante da competitividade (CASTILLO; FREDERICO, 2010; CASTILLO, 2011; ZYLBERSZTAJN, 2014; CASTILLO et al., 2016).

O aumento da demanda e diversificação de produtos agrícolas (tanto no Brasil quanto no mundo), a expansão da dinâmica urbano-industrial, a necessidade de equilibrar a balança comercial brasileira para gerar superavit, e a exigência do mercado para melhorar a produtividade do campo, são fatores que contribuíram sobremaneira para a implantação de um novo modelo produtivo de agricultura. As pressões do mercado foram decisivas para estimular o aumento do consumo de inovações científico-tecnológicas no campo e promover uma reestruturação organizacional e institucional das atividades agropecuárias. Essa modernização ocorreu via lógica liberal de mercado, com etapas do processo produtivo e logístico controladas sob operacionalidade empresarial que, no primeiro momento, foram centralizadas por ações reguladoras do Estado.

Como a modernização da agricultura exigiu a sua plena industrialização, ou seja, o maior consumo de bens de produção e de capital fabricados industrialmente e o processamento agroindustrial das matérias-primas, o setor rural acabou sendo gradativamente aproximado/subordinado/integrado à dinâmica urbano-industrial, o que favoreceu a emergência de diferentes formas de capital extracampo (industrial, comercial e financeiro) na regulação das atividades agrícolas. Logo, o campo tornou-se alvo crescente de interesses corporativos, influenciando o mercado agropecuário e as políticas de desenvolvimento do campo, que passaram a ser regidas segundo benesses dos agentes hegemônicos (latifundiários, agroindústrias, cooperativas, tradings, bancos etc.). O resultado, evidentemente, foi uma modernização da agricultura de forma desigual, seletiva e conservadora ${ }^{1}$, do ponto de vista agrário.

Isto porque, no atual período histórico da globalização do capitalismo neoliberal (SANTOS, 2000; HARVEY, 2005), o conjunto dos objetos técnico-científicos, recursos financeiros e ações normativas geralmente não se distribuem de forma homogênea entre os agentes e lugares. No caso do setor agropecuário, as suas sucessivas reestruturações técnicas e 
organizacionais tiveram um caráter puramente econômico, setorial e produtivista, embasadas fundamentalmente na ideologia da acumulação ampliada do capital (OLIVEIRA, 2016), beneficiando principalmente os agentes e espaços mais capitalizados e/ou com maior potencial de atender as exigências imediatas do mercado nacional e internacional.

Muitos agentes (agricultores familiares, camponeses, trabalhadores rurais, populações rurais tradicionais, extrativistas) e lugares (interior do Brasil com baixo potencial de produção de commodities agrícolas, sobretudo em áreas da região Norte e Nordeste) não participaram efetivamente da modernização do campo, ficando à mercê do mercado, o que acentuou as desigualdades sociais e regionais no território brasileiro. Além disso, os agentes menos privilegiados, sobretudo em áreas de avanço da fronteira agrícola moderna (FREDERICO, 2010, 2013), são atingidos por incisivas formas de acumulação por despossessão/espoliação (HARVEY, 2005), praticadas pelos agentes hegemônicos do capital.

Tendo em vista a evolução da atividade agropecuária moderna brasileira e suas implicações territoriais, o presente texto objetiva discutir, brevemente, o processo de consolidação do agronegócio globalizado no Brasil, que na atualidade se fundamenta, em seu conteúdo político e econômico, no Neoliberalismo. A exacerbada especialização econômica e a competitividade geográfica, a que várias regiões e seus respectivos municípios são submetidos para a produção e exportação de commodities agrícolas, tem evidenciado profundas desigualdades socioespeciais e uma vulnerabilidade territorial crescente.

\section{DOS COMPLEXOS AGROINDUSTRIAIS À AGRICULTURA CIENTÍFICA GLOBALIZADA}

A constituição do agronegócio globalizado do Brasil é um processo que remonta aos meados da década de 1960, com o início da modernização e desenvolvimento do capitalismo na agricultura. Para Castillo (2007) e Frederico (2013), a agropecuária brasileira passou por dois períodos recentes de modernização: o primeiro ocorreu entre os anos 1960 e 1980, com a internalização do paradigma da Revolução Verde, a formação dos complexos agroindustriais (CAI's) e a centralidade do Estado; e o segundo a partir de 1990, com a emergência da agricultura científica globalizada (SANTOS, 2000), decorrente da difusão de novos objetos e ações ligadas ao meio técnico-científico-informacional em todas as etapas da produção e circulação, especialmente de commodities $^{2}$.

Em se tratando do primeiro momento da modernização, Delgado (1985) aponta que fatores, como a constituição de uma sociedade cada vez mais urbano-industrial, o crescente aumento do emprego não agrícola, a conjuntura comercial internacional favorável às exportações e a necessidade do país em realizar exportações para o pagamento da crescente dívida externa, permitiram o aumento da demanda de produtos agropecuários e a sua diversificação. De acordo com dados dos Censos Demográficos do IBGE, a população urbana passou de 18 milhões em 1950 para mais de 110 milhões em 1991. A taxa de urbanização, por 
sua vez, saltou de $36 \%$ para $75 \%$ (Tabela 1.1 ), o que significou a necessidade de expandir a produção interna de alimentos.

Tabela 1 - Brasil: população total e urbana e índice de urbanização, 1950-2010

\begin{tabular}{cccc}
\hline Ano & $\begin{array}{c}\text { População } \\
\text { total }\end{array}$ & $\begin{array}{c}\text { População } \\
\text { urbana }\end{array}$ & $\begin{array}{c}\text { Índice de } \\
\text { urbanização }\end{array}$ \\
\hline 1950 & 51.944 .397 & 18.782 .891 & 36,1 \\
1960 & 70.192 .343 & 32.004 .817 & 45,0 \\
1970 & 94.508 .583 & 52.904 .744 & 55,9 \\
1980 & 121.150 .573 & 82.013 .375 & 67,7 \\
1991 & 146.917 .549 & 110.875 .826 & 75,5 \\
2000 & 169.590 .693 & 137.755 .550 & 81,2 \\
2010 & 190.755 .799 & 160.925 .792 & 84,3 \\
\hline
\end{tabular}

Fonte: Censo Demográfico (IBGE, 2020). Organização: dos autor(a)s

Gonçalves Neto (1997) mostra que entre os anos de 1950 e 1960 havia um discurso que apregoava o grande atraso da agricultura e sua ineficiência funcional frente à moderna sociedade urbano-industrial, justificando os interesses dos agentes hegemônicos da economia (grandes empresas, Estado, latifundiários) em modernizar o setor agropecuário para atender as demandas do mercado. De acordo com a discussão apresentada pelo autor, a agricultura se colocava como um entrave ao processo de desenvolvimento econômico devido a vários fatores inter-relacionados: ao monopólio da propriedade da terra (existência de muitos latifúndios tradicionais e improdutivos), à baixa produtividade (técnicas arcaicas de produção), preços elevados das matérias-primas (forte transferência do rendimento industrial para o setor rural), incipiente presença do assalariamento rural coexistindo com formas de produção de subsistência (limitação às possibilidades de expansão do mercado interno urbano-industrial) e baixo uso de tecnologia (pouca demanda de bens de capital e produção agrícola industrializados). A partir de então, se institucionaliza um projeto estatal de modernização do campo, baseado em diversas políticas de estímulo ao setor agropecuário.

Uma das medidas mais importantes para a modernização das atividades agropecuárias foi o acesso e implantação do pacote de inovações científico-tecnológicas (mecânicas, físico-químicas e biológicas) nos processos de produção agrícola, paradigma inspirado em países desenvolvidos (principalmente da Europa e nos Estados Unidos), que era denominado de "Revolução Verde" (DELGADO, 1985). As inovações compreendiam maquinários e implementos agrícolas, fertilizantes e defensivos químicos, mudas e sementes melhoradas, calendário agrícola, irrigação, rações e medicamentos para animais etc. Para Delgado (1985, p. 96), a Revolução Verde "combina inovações físico-químicas e mecânicas com a criação de variedades vegetais altamente exigentes em adubação química e irrigação...". O acesso a essas inovações foi facilitado, sobretudo, mediante o Sistema Nacional de Crédito Rural (SNCR), programa criado pelo governo federal para financiar a compra de insumos e maquinários agrícolas pelos produtores rurais (KAGEYAMA, 1990). Essa política foi estratégica, pois “a modernização da agricultura requer a existência de um sistema financeiro constituído 
(concretizado inicialmente no SNCR) para que possa ser viabilizada e, ao mesmo tempo, esse sistema passa a ser fundamental na soldagem dos CAIs com o movimento global da acumulação" (GRAZIANO DA SILVA, 1998, p. 26). Mazzali (2000) afirma que a indução do setor financeiro beneficiou estruturalmente a economia agrícola, pois:

\begin{abstract}
O crédito farto com taxas de juros altamente subsidiadas visou favorecer o setor agropecuário em seu conjunto, tendo como clientela preferencial o produtor (modernizado ou modernizável), privilegiando, por meio das diferentes modalidades (investimento, comercialização e custeio), a indústria de bens de capital produtora de veículos, máquinas e implementos agrícolas, além de equipamentos de beneficiamento e de armazenagem. Também foram beneficiadas as cooperativas agrícolas, a indústria processadora e as indústrias química e petroquímica, produtoras de fertilizantes e defensivos agrícolas (MAZZALI, 2000, p. 23).
\end{abstract}

Segundo Delgado (1985, p. 92), a política de difusão da tecnologia derivada da Revolução Verde baseou-se em três características principais:

1) adaptação das inovações biológicas às estratégias industriais das inovações mecânicas e físico-químicas;

2) estreita vinculação da adoção tecnológica à política de crédito rural e aos serviços de assistência técnica governamental;

3) inovações, em geral apoiadas numa matriz energética intensiva no uso de derivados do petróleo.

Conforme Kageyama (1990) e Graziano da Silva (1998), em um primeiro momento desse período, essas inovações científico-tecnológicas foram maciçamente importadas, dada a inexistência de indústrias de bens de consumo e de capital agrícola instaladas no país. Já em um segundo momento, a modernização da base técnica no campo avança, efetivamente, com a internalização da fabricação dos insumos agrícolas no território brasileiro, a partir do desenvolvimento de grandes empresas químicas e mecânicas nacionais e, sobretudo, das transnacionais, que começam a se instalar no país para explorar o novo mercado agrícola em expansão.

Juntamente com a indústria de bens de consumo e de capital agrícola, constituiu-se também a indústria de beneficiamento/processamento de produtos agrícolas ou as agroindústrias, marcando então o que Kageyama et al. (1990) e Graziano da Silva (1998) chamaram de "industrialização da agricultura". Segundo Graziano da Silva (1998, p. 32), esse processo ocorreu "pelo aprofundamento da divisão do trabalho, aonde a agricultura se converteu num ramo da produção industrial, que compra insumos e vende matérias-primas para outros ramos industriais". A maior integração e/ou subordinação da agricultura à indústria e ao capital comercial e financeiro formou os chamados Complexos Agroindustriais ${ }^{3}$ que, para Delgado (1985), representam a "fusão ou integração de capitais intersetoriais". Sobre essa nova dinâmica da agricultura, Graziano da Silva (1998) pontua que:

Agora a dinâmica da agricultura estará determinada pelo padrão de acumulação industrial, centrado no desenvolvimento dos complexos agroindustriais, e a ação do Estado nesse contexto orienta-se para a modernização da agricultura, visando integrá-la ao novo circuito 
produtivo liderado pela indústria de insumos e processamento de matéria-prima e gerando as condições infraestruturais necessárias à expansão do conjunto do setor (GRAZIANO DA SILVA, 1998, p. 23).

O processo de modernização da agricultura teve, portanto, participação fundamental do Estado, no qual foi centralizada. Segundo Delgado (1985), Kageyama (1990), Gonçalves Neto (1997) e Graziano da Silva (1998), as principais políticas deliberadas pelos governos para estimular esse processo foram: fornecimento de crédito subsidiado para custeio; investimento e comercialização de produtores rurais e agroindustriais; garantia da política de preço mínimo e seguro safra aos produtores rurais e comerciantes; estímulo à entrada e instalação de empresas transnacionais de bens de produção e de capital agrícola (insumos químicos e mecânicos) e processadoras; articulação das empresas públicas de pesquisa agropecuária (como a Empresa Brasileira de Pesquisa Agropecuária - EMBRAPA, criada em 1973) com essas grandes empresas; oferta de assistência técnica e incentivo à extensão rural (como a Empresa Brasileira de Assistência Técnica e Extensão Rural - EMBRATER, criada em 1974 e extinta em 1990), difundindo as novas técnicas de manejo; criação de uma rede de armazéns públicos; investimentos em sistemas de transporte (rodovias, ferrovias, portos) e energia (produção, transmissão e distribuição); e promoção da ocupação e colonização de fronteiras agrícolas.

Observa-se então, desde o início, uma estrita parceria estratégica entre o Estado e o mercado na condução de ações que levaram ao processo de reestruturação produtiva, através da constituição de um meio técnico-científico (SANTOS, 1996; SANTOS; SILVEIRA, 2001) no campo brasileiro. Sobre essa parceria, Hespanhol (2007) observa que:

\footnotetext{
Muitas indústrias vinculadas à agropecuária se implantaram no país ao longo dos anos $60 \mathrm{e}$ 70, em razão dos estímulos oferecidos pelo Estado e do promissor mercado brasileiro, que foi artificialmente ampliado pelas políticas modernizantes, notadamente pela oferta de crédito rural em grande volume e por baixas taxas de juros para a aquisição de máquinas, implementos e insumos químicos (HESPANHOL, 2007, p. 190).
}

No entanto, essas políticas de desenvolvimento, ou melhor, de modernização rural, não atingiram igualmente todos os agentes e lugares do território brasileiro, revelando um caráter profundamente conservador e seletivo do ponto de vista social, setorial e regional. Um exemplo são os dados apresentados por Gonçalves Neto (1997), mostrando que a maior quantidade de contratos de crédito rural entre os anos 1966 e 1976 eram celebrados por pequenos produtores rurais (pois em número de estabelecimentos eram a maioria no país, representando mais de $85 \%$ do total, segundo os Censos Agropecuários do IBGE de 1940 até 2006). Porém, o maior volume desses recursos foi sendo destinado principalmente aos médios e grandes produtores ao longo do tempo (Tabela 2). Soma-se a isso o fato de que, conforme estimativas apontadas por Gonçalves Neto (1997, p. 171), apesar de ter havido um aumento substancial do número de contratos e de recursos disponibilizados, somente uma pequena parte do total de produtores rurais do país (em torno de $20 \%$ a $25 \%$ ) era atendida pelo SNCR, o que representava ainda menos chances de financiamento aos pequenos ${ }^{3}$. 
A mesma disparidade ocorreu em relação à oferta de crédito de custeio segundo o tipo de cultura agrícola. Boa parte dos recursos (60\%) eram destinados à produção de produtos comumente voltados à exportação, como o café, milho, soja, trigo e cana-de-açúcar (açúcar) nos anos de 1970 (Tabela 3). A distribuição do crédito também foi desigual em termos regionais. Segundo dados apresentados por Matos; Pessôa (2011), as regiões Sul e Sudeste concentraram $77 \%$ dos recursos até 1970 , passando a $65 \%$ nos anos seguintes, enquanto nas duas maiores regiões brasileiras (Norte e Nordeste), a participação reduziu-se de 23\% para $10,8 \%$ no mesmo período (Tabela 4 ).

Tabela 2 - Brasil: número de contratos $(\mathrm{C})$ e do valor financiado $(\mathrm{V})$ à agricultura e à pecuária, por classes de produtores, 1966-1976

\begin{tabular}{|c|c|c|c|c|c|c|c|c|c|c|c|c|}
\hline \multicolumn{7}{|c|}{ Agricultura } & \multicolumn{6}{|c|}{ Pecuária } \\
\hline \multirow[t]{2}{*}{ Ano } & \multicolumn{2}{|c|}{ Pequ. Prod. } & \multicolumn{2}{|c|}{$\begin{array}{l}\text { Médio. } \\
\text { Prod. }\end{array}$} & \multicolumn{2}{|c|}{$\begin{array}{l}\text { Grande } \\
\text { Prod. }\end{array}$} & \multicolumn{2}{|c|}{ Pequ. Prod. } & \multicolumn{2}{|c|}{$\begin{array}{l}\text { Médio. } \\
\text { Prod. }\end{array}$} & \multicolumn{2}{|c|}{$\begin{array}{c}\text { Grande } \\
\text { Prod. }\end{array}$} \\
\hline & $\mathrm{C} \%$ & $\mathrm{~V} \%$ & $\mathrm{C} \%$ & V\% & $\mathrm{C} \%$ & $\mathrm{~V} \%$ & $\mathrm{C} \%$ & $\mathrm{~V} \%$ & $\mathrm{C} \%$ & $\mathrm{~V} \%$ & $\mathrm{C} \%$ & $\mathrm{~V} \%$ \\
\hline 1966 & 90,0 & 43,1 & 9,5 & 45,6 & 0,4 & 20,2 & 81,4 & 33,2 & 18,3 & 54,4 & 0,2 & 12,3 \\
\hline 1967 & 88,4 & 32,2 & 10,9 & 47,2 & 0,6 & 20,5 & 82,7 & 39,2 & 17,0 & 55,3 & 0,2 & 5,5 \\
\hline 1968 & 87,2 & 31,0 & 12,2 & 49,7 & 0,5 & 19,2 & 84,4 & 39,5 & 15,3 & 45,9 & 0,2 & 14,5 \\
\hline 1969 & 88,1 & 30,9 & 11,1 & 45,8 & 0,7 & 23,2 & 86,8 & 42,5 & 12,9 & 42,1 & 0,3 & 15,3 \\
\hline 1970 & 85,9 & 27,5 & 13,2 & 47,1 & 0,8 & 25,2 & 84,5 & 39,4 & 15,2 & 45,9 & 0,2 & 14,6 \\
\hline 1971 & 85,7 & 24,6 & 13,2 & 44,0 & 1,0 & 31,4 & 80,3 & 30,3 & 19,0 & 51,2 & 0,6 & 18,4 \\
\hline 1972 & 83,5 & 20,6 & 14,9 & 42,1 & 1,5 & 37,1 & 79,8 & 29,0 & 19,4 & 50,1 & 0,7 & 21,0 \\
\hline 1973 & 79,4 & 17,2 & 18,5 & 38,7 & 2,0 & 44,0 & 71,0 & 17,4 & 27,3 & 47,6 & 1,7 & 34,9 \\
\hline 1974 & 76,6 & 15,1 & 20,9 & 37,4 & 2,5 & 47,4 & 70,4 & 17,2 & 27,4 & 48,4 & 2,1 & 34,3 \\
\hline 1975 & 74,1 & 11,7 & 22,4 & 34,2 & 3,3 & 54,0 & 67,0 & 15,0 & 30,0 & 49,5 & 2,9 & 35,4 \\
\hline 1976 & 73,7 & 11,3 & 23,0 & 35,0 & 3,3 & 53,5 & 69,0 & 12,1 & 27,4 & 41,0 & 3,8 & 46,9 \\
\hline
\end{tabular}

Fonte: Gonçalves Neto (1997, p. 174)

Tabela 3 - Brasil: participação (\%) de alguns produtos no crédito rural de custeio, 1973-1977

\begin{tabular}{lccccc}
\hline \multicolumn{1}{c}{ Produto } & $\mathbf{1 9 7 3}$ & $\mathbf{1 9 7 4}$ & $\mathbf{1 9 7 5}$ & $\mathbf{1 9 7 6}$ & $\mathbf{1 9 7 7}$ \\
\hline Algodão & 7,6 & 8,7 & 4,7 & 6,5 & 7,2 \\
Arroz & 11,8 & 14,5 & 17,6 & 15,0 & 15,1 \\
Café & 15,2 & 14,5 & 9,6 & 10,8 & 12,2 \\
Cana-de-açúcar & 6,6 & 8,9 & 10,7 & 9,7 & 8,2 \\
Feijão & 2,6 & 1,9 & 1,4 & 1,8 & 3,2 \\
Mandioca & 0,6 & 0,4 & 0,4 & 0,8 & 0,9 \\
Milho & 11,3 & 10,2 & 10,7 & 10,0 & 7,6 \\
Soja & 14,6 & 16,9 & 17,3 & 19,1 & 19,1 \\
Trigo & 4,4 & 9,7 & 12,4 & 12,0 & 10,0 \\
Outros & 25,3 & 14,3 & 15,2 & 14,3 & 16,5 \\
\hline
\end{tabular}

Fonte: Gonçalves Neto (1997, p. 176) 
Tabela 4 - Brasil: participação (\%) das regiões no crédito rural, 1966-1999/00 (anos selecionados)

\begin{tabular}{lccccc}
\hline \multicolumn{1}{c}{ Anos } & Sudeste & Sul & Centro-Oeste & $\begin{array}{c}\text { Norte/Nordest } \\
\text { e }\end{array}$ & Brasil \\
\hline 1966 & 47,0 & 30,0 & - & 23,0 & 100,0 \\
1970 & 45,6 & 31,8 & 6,5 & 16,1 & 100,0 \\
1975 & 35,7 & 38,2 & 10,1 & 15,0 & 100,0 \\
1980 & 34,1 & 35,8 & 10,5 & 19,6 & 100,0 \\
$1985 / 86$ & 28,2 & 37,6 & 18,1 & 16,1 & 100,0 \\
$1988 / 89$ & 21,1 & 34,5 & 32,9 & 11,3 & 100,0 \\
$1991 / 92$ & 21,5 & 47,3 & 21,5 & 9,6 & 100,0 \\
$1994 / 95$ & 26,6 & 38,9 & 21,1 & 13,3 & 100,0 \\
$1997 / 98$ & 30,6 & 37,1 & 18,5 & 12,9 & 100,0 \\
$1999 / 00$ & 28,7 & 42,1 & 18,4 & 10,8 & 100,0 \\
\hline
\end{tabular}

Fonte: Matos; Pêssoa (2011, p. 303)

Ainda, segundo Gonçalves Neto (1996), outras políticas estatais como a garantia de preços mínimos, seguro agropecuário, pesquisa agropecuária, assistência técnica e extensão rural e programas de estímulo à produção de insumos químicos-biológicos e maquinários agrícolas, foram oferecidas de forma seletiva, em termos de agentes, produtos e regiões.

No caso da política de preços mínimos, os recursos atendiam principalmente os médios e grandes produtores, além das agroindústrias, cooperativas e comerciantes, já que os pequenos produtores, dada a sua escassez de recursos e a falta de apoio governamental, possuíam pouca facilidade de acesso ao programa (burocracia; meios precários de acompanhamento dos preços, do planejamento agrícola, do transporte, da classificação e armazenamento etc.). Os recursos desta política concentravam-se também em poucos produtos (algodão, soja, arroz e milho chegaram a somar $90 \%$ dos empréstimos para estocagem, embora a política previsse trabalhar com a sustentação de quarenta tipos de produtos agrícolas) e atendiam prioritariamente as áreas do Centro-Sul (Sudeste, Sul e Centro-Oeste recebiam mais de $80 \%$ do total dos empréstimos para estocagem) (GONÇALVES NETO, 1996). A inexpressiva participação do governo nas operações de aquisição de produtos e o estabelecimento de preços mínimos pouco rentáveis aos agricultores se constituíram em mais uma problemática.

Outro exemplo é a pesquisa agropecuária, que desde o início privilegiou o desenvolvimento de inovações científico-tecnológicas para determinadas culturas, como grãos, cana-de-açúcar e pecuária, e aplicáveis em sua maior parte às áreas de grande potencial produtivo, como às do domínio morfoclimático do Cerrado (BERNARDES, 2015). Sendo assim, atendeu satisfatoriamente as regiões, produtos e processos produtivos mais demandados pelo mercado industrial (insumos agrícolas e processamento), latifundiário (produção agrícola e terras), comercial (tradings e cooperativas) e financeiro (commodities, financiamento agrícola). 
Já no caso da política de ocupação de terras públicas, Palmeira (1989) destaca que os mecanismos de transferência maciça do patrimônio fundiário da Nação, sendo as licitações (os leilões) o mais utilizado, beneficiavam principalmente grandes fazendeiros e grupos econômicos nacionais e estrangeiros interessados na terra como reserva de valor. Isso acontecia devido a vários motivos: oferta de lotes muito grandes de terras (500 a 3.000 hectares, o que diminuía as oportunidades de compra por pequenos proprietários, que se encontravam descapitalizados), inexistência de limitações à aquisição de vários lotes por um mesmo grupo empresarial, debilidade no reconhecimento das posses das terras, e editais e projetos bastante burocráticos (PALMEIRA, 1989). Esses problemas dificultavam a participação mais efetiva dos pequenos produtores nas licitações, promovendo uma verdadeira exclusão daqueles que mais necessitavam de terras para expandir a produção e se manter no campo.

Tendo em conta o panorama em que foi se estruturando o novo modelo de economia agropecuária brasileira, Gonçalves Neto (1997, p. 122) sintetiza esse primeiro momento da modernização dizendo que:

Em suma, estamos tentando chamar a atenção para o fato de que a política agrícola colocada em prática pelo governo brasileiro, no período estudado (1960-1980), terá por objetivo básico manter inalteradas as formas de acumulação dominantes na sociedade, compatibilizando interesses díspares de setores que lutam pelo controle dos principais fatores econômicos. Promove, portanto, a modernização de grande parte da agricultura, aumenta a produtividade sem, contudo, tocar nos padrões de acumulação.

A partir da década 1980, mudanças de ordem técnica e normativa atingiram o setor agropecuário brasileiro em decorrência da crise fiscal (elevada dívida pública interna e externa e poupança pública negativa) e monetária (inflação, desvalorização cambial) vivenciada pelo Estado, bem como da crise econômica internacional (associada aos transtornos provocados pelo "choque do petróleo" de 1979). Essas mudanças estão ligadas à redução do aparato estatal no processo de modernização do campo (retração na oferta do crédito e nos investimentos em infraestrutura), à gradativa centralização dos investimentos e regulação do comércio pelas grandes empresas, e à reestruturação tecnológica e organizacional (MAZZALI, 2000; DELGADO, 2012; VIEIRA FILHO, 2014). Nesse momento, segundo Mazzali (2000, p. 34), "o que se obteve não foi a recuperação da capacidade de intervenção do Estado, mas, ao contrário, a sua desarticulação e imobilização". E ainda:

\footnotetext{
Com a redução do grau de indução, pelo Estado, e no contexto de profundas transformações nos mercados e na concorrência, enfraqueceram-se as bases que sustentavam as articulações entre os agentes, deixando "em aberto" o campo de opções estratégicas e propiciando, assim, o ambiente para a reestruturação das relações. A partir daí, as articulações intra e intersetores ficaram por conta das estratégias do setor privado (MAZZALI, 2000, p. 36).
}

Frederico (2013), a partir de Mazzali (2000), explica que com essas mudanças, um novo padrão de organização do agronegócio emergiu no Brasil a partir da década de 1990. De acordo com o autor, este modelo diferencia-se do padrão anterior graças a três aspectos 
básicos: a) aperfeiçoamento e, em certa medida, a superação do padrão tecnológico difundido pelo paradigma da Revolução Verde, com a adoção das Novas Tecnologias de Informação e Comunicação (NTICs), como a informática, a microeletrônica, a biotecnologia, a engenharia genética e a formação e transmissão de bancos de dados ${ }^{5}$; b) o aumento das exportações de produtos primários (soja, milho, açúcar, café em grão, carnes, etc., de baixo valor agregado) em detrimento dos produtos processados; c) e a menor atuação do Estado como principal regulador da agricultura, com a privatização e/ou sucateamento da maioria das empresas e instituições públicas responsáveis pelos diferentes aspectos da produção agrícola (extinção do Instituto do Açúcar e do Álcool - IAA e Instituto Brasileiro do Café - IBC, por exemplo). Assim:

\begin{abstract}
Juntamente com a "desregulamentação" dos mercados e a maior abertura comercial houve também uma maior internacionalização dos circuitos espaciais produtivos agrícolas. O padrão agrícola pautado nos complexos agroindustriais e na centralidade do Estado cede lugar a uma agricultura científica globalizada organizada em rede (Mazzali, 2000), cuja produção tem uma referência mundial - sobretudo, por meio da especialização na produção de commodities -, regulada pelas grandes corporações e refém das oscilações das cotações das principais bolsas de valores (FREDERICO, 2013, p. 4).
\end{abstract}

Para Mazzali (2000), o modelo de desenvolvimento via CAI entra em esgotamento face às mudanças de ordem econômica, política e tecnológica que ocorreram a partir de 1980, de âmbito nacional e internacional, transicionando para um novo paradigma produtivo pós década de 1990, através da complexificação das relações e organização dos agentes que conformam as cadeias agroindustriais (SAES; SILVEIRA, 2014). No novo padrão de modernização, além da economia agropecuária passar a ter uma regulamentação proeminentemente privada, "as relações entre as empresas não conhecem qualquer tipo de fronteira - geográfica, setorial ou empresarial. Nesse sentido, ao quebrar limites geográficos, a organização 'em rede' consegue captar o movimento recente de globalização" (MAZZALI, 2000, p. 156-157).

Isto porque tornou-se muito comum que uma única corporação, grupo empresarial ou instituição financeira ${ }^{6}$ atue diretamente ou por participação acionária, tanto em diversos ramos agrícolas e/ou agroindustriais (grãos, carnes, café, sucroenergético, algodão, etc.), quanto em vários elos da cadeia (produção e distribuição de bens de produção e capital agrícola, financiamento, PD\&I, produção da matéria-prima, processamento, logística, comercialização) e, portanto, em muitos lugares produtivos, através da expansão das redes verticais e horizontais $^{7}$ do agronegócio (MAZZALI, 2000). Dessa forma, modificou-se completamente a antiga linearidade dos esquemas dos Complexos Agroindustriais, em que cada elo e ramo específico era comandado por agentes distintos (modelo desverticalizado).

Por sua vez, com a maior participação de agentes privados altamente capitalizados e financeirizados no agronegócio, houve, além do controle seletivo das etapas de produção e circulação de mercadorias (FREDERICO, 2010), o aumento significativo dos investimentos em ampliação e modernização dos segmentos agrícola, agroindustrial, logístico e Pesquisa, Desenvolvimento e Inovação (PD\&I). No que concerne à PD\&I, a busca pelo aumento da 
produtividade, pela redução de custos, pelo ganho de eficiência e pela maximização dos lucros das grandes firmas motivou a difusão de diversas inovações científico-tecnológicas nas etapas de produção e circulação do agronegócio nos últimos anos (SILVEIRA, 2014; BUAINAIN et al., 2015). Segundo Elias (2003), a aplicação de procedimentos e métodos científicos nas várias etapas da produção agropecuária e agroindustrial marca uma nova racionalidade técnica no campo, consolidando uma verdadeira agricultura científica. Os principais resultados deste novo padrão agrícola foram: o maior controle sobre as condições naturais, o relativo aumento da produtividade (trabalho e terra), redução dos custos de produção, o encurtamento do ciclo vegetativo e a constituição de uma logística mais eficiente (ELIAS, 2003, 2007, 2013). Isto favoreceu a ampliação dos lucros e o retorno mais rápido dos investimentos realizados pelas grandes empresas.

A intensificação do uso das NTCIs nos processos de produção e circulação do agronegócio é o principal fator favorável ao aumento da produtividade e rentabilidade desse novo momento da agropecuária brasileira. Dentre as principais tecnologias adotadas, destacam-se a biotecnologia, a agricultura de precisão, a criação de banco de dados sobretudo em Sistemas de Informações Geográficas (SIG), automação e monitoramento em tempo real de riscos climáticos, das etapas agrícolas, agroindustriais e logísticas, bem como da movimentação do mercado financeiro, entre outros (ARACRI, 2012; MASSRUHÁ et al., 2014).

Para Santos (2000), esse tipo de agricultura é exigente em ciência, tecnologia e informação e demanda uma enorme racionalidade externa, como o uso de modernos bens de capital e produção (insumos físico-químicos, mecânicos e biológicos) e a padronização dos procedimentos (preparação do terreno, plantio, tratos culturais, colheita, armazenamento, transporte, beneficiamento e comercialização). Isto, completa o autor, leva "à introdução, aprofundamento e difusão de processos racionalizados que se contagiam mutuamente, propondo a instalação de sistemismos, que atravessam o território e a sociedade, com a racionalização de práticas, a uma certa homogeneização" (SANTOS, 2000, p. 89). Como destaca ainda Santos (2000, p. 88-89),

\footnotetext{
Podemos agora falar de uma agricultura científica globalizada. Quando a produção agrícola tem uma referência planetária, ela recebe influência daquelas mesmas leis que regem os outros aspectos da produção econômica. Assim, a competitividade, característica das atividades de caráter planetário, leva a um aprofundamento da tendência à instalação de uma agricultura científica. Esta, como vimos, é exigente de ciência, técnica e informação, levando ao aumento exponencial das quantidades produzidas em relação às superfícies plantadas. Por sua natureza global, conduz a uma demanda extrema de comércio. O dinheiro passa a ser uma “informação" indispensável.
}

De acordo com Castillo (2011), a crescente adoção de parâmetros internacionais de qualidade e custos, em prol da maior eficiência produtiva e da competitividade, tem resultado numa nova divisão territorial do trabalho, cujo controle técnico e principalmente político (regulação) passa a ser desempenhado por agentes situados em lugares distantes da produção. 
Embora o Estado tenha reduzido drasticamente a sua regulação na economia agropecuária, algumas de suas competências ainda são fundamentais para o desenvolvimento do setor, como a realização de parte das pesquisas agronômicas e formação de mão de obra; o fornecimento de parte do crédito para custeio, investimento e comercialização, sobretudo para construção e ampliação/modernização de sistemas logísticos (ferrovias, rodovias, hidrovias, portos); a fiscalização do mercado (via agências reguladoras); a concessão de incentivos fiscais e econômicos; a promoção das exportações etc. (GRAZIANO DA SILVA, 1998; FREDERICO, 2010; DELGADO, 2012; BUAINAIN et al., 2014). Estas ações estabeleceram um pacto pela economia política do agronegócio (DELGADO, 2012) e viabilizaram a fluidez dos circuitos espaciais produtivos de commodities agrícolas. Essa nova atuação do Estado brasileiro converge, assim, com o modelo de economia política intrínseco ao Neoliberalismo, cuja função passa a ser o de criar e manter um ambiente favorável aos negócios e assegurar os direitos individuais à propriedade privada, à promoção da riqueza e ao livre mercado.

\section{NEOLIBERALISMO, AGRONEGÓCIO GLOBALIZADO E VULNERABILIDADE TERRITORIAL}

As recentes transformações ocorridas no setor agropecuário brasileiro estão associadas, todavia, ao modelo de economia política do Neoliberalismo (HARVEY, 2005; BRENNER; PECK; THEODORE, 2012; DARDOT; LAVAL, 2016) que se consolidou no país desde 1990. Esse modelo, em sua lógica geral, se caracteriza por um conjunto de normas, políticas, comportamentos e ações dos Estados, das empresas e também dos indivíduos que visam, basicamente, promover maior desenvolvimento econômico em um sistema com maior liberdade dos mercados, cumprimento de metas de competitividade e ações de controle estatais na economia mais restritivas e alinhadas às demandas e interesses das empresas corporativas. Para Dardot; Laval (2016), o Neoliberalismo se transformou, na era contemporânea, em uma nova racionalidade hegemônica da sociedade implicada pela globalização capitalista e pelo processo de acumulação ampliada do capital, sobretudo no âmbito financeiro. Os agentes hegemônicos ganharam enorme poder sobre as estruturas da economia política mundial e estenderam seus princípios, valores e domínios de operação para o todo o restante da sociedade, adotando uma racionalidade cuja permanência e sobrevivência no mercado depende cada vez mais das leis da concorrência e da competitividade.

Para Ioris (2016, 2018a, 2018b), o atual sistema agroalimentar hegemônico pode ser denominado de agro-neoliberalismo, o qual, segundo ele, se estrutura na interação de três dimensões: 1) renovadas alianças público-privadas, entre as grandes corporações transnacionais e instituições multilaterais (Organização Mundial do Comércio - OMC, Banco Mundial) - responsáveis por organizar o mercado (produção e comercialização) - com o Estado, que opera na regulação deste mercado, na produção de conhecimento, na organização do trabalho, nos acordos comerciais e políticas monetárias, na proteção contra riscos de mercado e climáticos, na promoção da segurança alimentar, etc; 2) novas estratégias 
tecno-econômicas que intensificam a exploração sócio-ecológica, como o uso intensivo de soluções científico-tecnológicas derivadas das NTICs para maximizar a produtividade e a lucratividade da produção, logística e comercialização; 3) Contenção de reaçães críticas, através dos discursos corporativos e governamentais de sustentabilidade, segurança alimentar, desenvolvimento econômico e direito à propriedade privada (arcabouço ideológico). No que concerne à expansão do agroneoliberalismo no Brasil, Ioris (2018b, p. 79-80, tradução nossa) destaca que:

\footnotetext{
O agroneoliberalismo brasileiro tem envolvido um intricado processo de ganho econômico e modernização agressiva em conjunto com esforços sistemáticos de ocultar alianças estratégicas entre autoridades populistas e ideologias favoráveis ao mercado. O setor tem mantido taxas constantes de expansão não somente devido ao contínuo aprimoramento tecnológico (novos agroquímicos, sementes geneticamente modificadas e sofisticados maquinários e equipamentos digitais), mas também por causa do Land Grabbing e incorporação de novas áreas (Borras, Kay, Gómez, \& Wilkinson, 2012). O resultado é uma paradoxal combinação de alta rentabilidade e resultados positivos com aumento dos riscos socioambientais e concentração de poder das corporações e líderes políticos da bancada ruralista.
}

Como o dinheiro se tornou uma "informação" indispensável, a dinâmica atual da agropecuária brasileira também é marcada por um forte movimento de financeirização dos seus agentes e do mercado (VERDI; AOUN, 2009; DELGADO, 2012; CHENG; XIONG, 2013; BALESTRO; LOURENÇO, 2014; CLAPP, 2014; ISAKSON, 2014; MARTIN; CLAPP, 2015; PAULA; SANTOS; PEREIRA, 2015; BERNARDES et al., 2017; CLAPP; ISAKSON, 2018; MCGILL, 2018). A crescente dependência do setor em relação ao crédito agrícola e agroindustrial e a condução das ações de grandes empresas pelo sistema financeiro são aspectos centrais da financeirização. As atividades do agronegócio, que já passavam por forte processo de oligopolização, principalmente nos segmentos de fabricação de insumos (químicos, mecânicos e biológicos), produção e processamento vegetal e animal, comercialização e logística de commodities (tradings) (KAGEYAMA et al., 1990), agora passam também a ser controladas por poderosas holdings e grupos financeirizados, proprietárias de boa parte das ações de grandes empresas do agronegócio (OLIVEIRA, 2016). Castillo et al. (2016) observam que, além destes, recentemente verifica-se a presença de representantes do capital financeiro internacional nas atividades do agronegócio, "como fundos de pensão, empresas de private equity, fundações e instituições bancárias, por meio de participação societária nas empresas agrícolas e do controle direto e indireto da terra e demais recursos".

Assim, questões como o quê, quem, onde, como, quanto e quando produzir, armazenar, distribuir e comercializar, são cada vez mais ditadas pelas grandes empresas e seus investidores financeiros acionistas, que são constituídos por agentes que buscam constantemente formas de acumulação de capital através de novos investimentos rentáveis e mecanismos de especulação (CHESNAIS, 2005; BRUNHOFF, 2010).

Conforme Oliveira (2016), o caráter monopolista e financeiro da agricultura capitalista mundializada se estrutura a partir de três elementos: i) a produção de commodities; ii) as 
bolsas de mercadorias e de futuro; iii) os monopólios mundiais (grandes corporações transnacionais). O primeiro fator diz respeito ao fato de que vários produtos agrícolas, pecuários e minerais, se transformaram em commodities, ou seja, em mercadorias padronizadas qualitativamente que são comercializadas no mundo inteiro e negociadas em bolsas de valores, como o milho, trigo, arroz, soja, algodão, cacau, café, açúcar, suco de laranja, farelo e óleo de soja, petróleo, minério de ferro, entre outros. No Brasil, acrescenta-se também o etanol e o boi gordo, que embora não sejam commodities, são negociados no mercado futuro. $\mathrm{O}$ segundo fator refere-se ao fato de que as bolsas de mercadorias e futuro se tornaram o centro regulador dos preços mundiais de commodities, impondo severamente a busca por métodos de produção cada vez mais competitivos em termos de qualidade e custos. O terceiro fator está relacionado ao controle monopolista da produção, da logística e da comercialização das commodities por empresas mundiais, como a Bunge, a Cargill, a Archer Daniels Midland (ADM), a Louis Dreyfus Company (LDC), a Tereos e a Cofco, todas com capital aberto em bolsa de valores (exceto Cargill).

Várias empresas brasileiras do agronegócio também possuem capital aberto na Bolsa de Valor B3, atuando em ramos como: papel e celulose (Celulose Irani, Cia Melhoramentos de São Paulo, Klabin, Santher, Suzano); madeira (Duratex, Eucatex); agricultura (Brasilagro Cia Brasileira de Propriedades Agrícolas, CTC - Centro de Tecnologia Canavieira, Pomifrutas, SLC Agrícola, Terra Santa Agro); açúcar e etanol (Biosev, Raízen Energia, São Martinho); alimentos processados (Camil Alimentos, Conservas Oderich, Forno de Minas Alimentos, J. Macedo, Josapar-Joaquim Oliveira, M. Dias Branco) carnes e derivados (BRF, JBS, Marfrig, Excelsior Alimentos, Minerva, Minupar Participações); bebidas (Ambev); fertilizantes e defensivos (Fertilizantes Heringer, Nutriplant Industria e Comércio); maquinários e implementos agrícolas (Metisa Metalurgia Timboense, Siderurgia J. L. Aliperti, Stara Indústria de Implementos Agrícolas); logística (BBM Logística, CCR, Cosan Logística, Ferrovia Centro-Atlântica, Log-In Logística Intermodal, MRS Logística, Rumo Logística, JSL, Tegma Gestão Logística) e financeiro (ECO Securitizadora CRED Agronegócio, Gaia Agro) (B3, 2019). Tal fato evidencia, portanto, o processo de financeirização de grandes grupos do agronegócio do país.

O caráter globalizado da agricultura brasileira está associado ainda, além da presença de grandes transnacionais para a produção e comercialização de commodities, ao crescimento das demandas internacionais urbanas por produtos alimentares semiprocessados e ultraprocessados. Segundo Elias (2003, 2013a, 2021a), a difusão de um padrão estandardizado de consumo alimentar foi responsável por criar novas mercadorias e modificar hábitos e costumes da população. Este movimento é comandado, conforme discute a autora, por cadeias varejistas e atacadistas de grandes supermercados (Walmart, Costco, Kroger, Lidl Kaufland, Aldi, Carrefour, Aeon, Tesco, Target, Makro, Pão de Açúcar, Extra etc.), redes globais de fast foods (McDonald's, Habib's, Burger King, Bob's Burger, Giraffas, Pizza Hut, Ragazzo, Subway, KFC, Domino's, Taco Bell, Dunkin' Donuts etc.), restaurantes e bares, serviços de catering para hotéis e linhas aéreas, etc.; que "buscam homogeneizar o padrão de 
consumo alimentar, violando identidades locais baseadas em saberes e fazeres historicamente construídos" (ELIAS, 2003, p. 323).

Assim, constatamos a emergência do agronegócio globalizado na estrutura econômica brasileira e se consolidando como uma das principais atividades geradoras de acumulação de capital. Esse setor abrange um conjunto de atividades que se realizam de forma totalmente interligada e multiescalar, como a produção agropecuária (matérias-primas de origem animal e vegetal), indústrias (máquinas, implementos, insumos químicos e biológicos, agroindústrias etc.), serviços (centros de PD\&I, aviação agrícola, veterinária, informática, automação, contabilidade, marketing), comércio especializado no consumo produtivo do agronegócio (insumos químicos, mecânicos e biotecnológicos), financeiro (bancos, cooperativas de crédito, bolsa de valores, fundos de investimento), logística e distribuição (atacado e varejo) (ELIAS, 2007a, 2017a, 2021b).

Um dado que evidencia o ganho de participação do agronegócio na economia brasileira é a proporção de empresas vinculadas ao setor no conjunto das maiores empresas do país. De acordo com o Valor Econômico (2021), das 50 maiores empresas por receita líquida em 2012, 8 eram ligadas ao agronegócio, tendo representado $18 \%$ do total do faturamento da amostra. Já em 2019 esses números sobem para 14 empresas e uma participação de $32 \%$ do total, conforme podemos ver na Tabela 5 .

Tabela 5 - Brasil: ranking das 50 maiores empresas por receita líquida, 2012 e 2019

\begin{tabular}{|c|c|c|c|c|c|c|}
\hline \multirow[b]{2}{*}{ R. } & \multicolumn{3}{|c|}{2012} & \multicolumn{3}{|c|}{2019} \\
\hline & Empresa & $\begin{array}{l}\text { Receita líquida } \\
\text { (milhões de R\$) }\end{array}$ & $\begin{array}{l}\% \text { das } 50 \\
\text { Maiores } \\
\end{array}$ & Empresa & $\begin{array}{l}\text { Receita líquida } \\
\text { (milhões de R\$) }\end{array}$ & $\begin{array}{l}\% \text { das } 50 \\
\text { Maiores } \\
\end{array}$ \\
\hline 1 & Petrobras & $281.379,0$ & 20,1 & Petrobras & $302.245,00$ & 13,1 \\
\hline 2 & Vale & $93.511,0$ & 6,7 & JBS & $204.524,00$ & 8,8 \\
\hline 3 & JBS & $75.696,7$ & 5,4 & Vale & $148.640,00$ & 6,4 \\
\hline 4 & Ultra & $53.919,4$ & 3,9 & Raízen & $120.581,00$ & 5,2 \\
\hline 5 & Pão de Açúcar & $50.924,5$ & 3,6 & Petrobras Distribuidora & $94.985,00$ & 4,1 \\
\hline 6 & Gerdau & $38.443,3$ & 2,8 & Ultrapar & $89.298,00$ & 3,9 \\
\hline 7 & Bunge & 47.981,7 & 3,4 & Cosan & 72.979,70 & 3,2 \\
\hline 8 & Braskem & $35.513,4$ & 2,5 & Grupo Carrefour & $60.064,00$ & 2,6 \\
\hline 9 & Eletrobras & $34.064,5$ & 2,4 & GPA & $56.635,00$ & 2,4 \\
\hline 10 & Telefônica (Vivo) & $33.931,4$ & 2,4 & AmBev & $52.599,70$ & 2,3 \\
\hline 11 & AmBev & $32.231,0$ & 2,3 & Braskem & $52.323,50$ & 2,3 \\
\hline 12 & Cosan & $30.016,5$ & 2,1 & Marfrig & $48.761,10$ & 2,1 \\
\hline 13 & Odebrecht & $28.713,1$ & 2,1 & Cargill & $48.629,80$ & 2,1 \\
\hline 14 & BRF & $28.517,4$ & 2,0 & Telefônica (Vivo) & $44.268,20$ & 1,9 \\
\hline 15 & Carrefour & $27.367,3$ & 2,0 & ADM & $43.586,30$ & 1,9 \\
\hline 16 & Volkswagem & $26.627,0$ & 1,9 & Gerdau & $39.644,00$ & 1,7 \\
\hline 17 & $\mathrm{Oi}$ & $25.169,2$ & 1,8 & Bunge & $37.545,70$ & 1,6 \\
\hline 18 & Cargill & $24.186,4$ & 1,7 & Claro & $35.210,20$ & 1,5 \\
\hline
\end{tabular}




\begin{tabular}{|c|c|c|c|c|c|c|}
\hline 19 & Fiat Automóveis & $23.951,5$ & 1,7 & Fiat & $34.422,10$ & 1,5 \\
\hline 20 & Marfrig & $23.726,4$ & 1,7 & Enel Brasil & $33.711,70$ & 1,5 \\
\hline 21 & Walmart & $22.548,1$ & 1,6 & BRF & $33.447,00$ & 1,4 \\
\hline 22 & Embratel & $18.781,2$ & 1,3 & ArcelorMittal Brasil & $32.455,10$ & 1,4 \\
\hline 23 & TIM & $18.763,9$ & 1,3 & Shell & $32.375,00$ & 1,4 \\
\hline 24 & Cemig & $18.460,4$ & 1,3 & CPFL Energia & $29.932,50$ & 1,3 \\
\hline 25 & $\mathrm{CSN}$ & $16.896,3$ & 1,2 & Copersucar & $29.907,40$ & 1,3 \\
\hline 26 & ArcelorMittal Brasil & $15.704,0$ & 1,1 & Neoenergia & $28.461,30$ & 1,2 \\
\hline 27 & Honda & $15.564,4$ & 1,1 & Eletrobras & $27.725,50$ & 1,2 \\
\hline 28 & CPFL Energia & $15.055,1$ & 1,1 & Suzano & $26.013,00$ & 1,1 \\
\hline 29 & Copersucar & $14.741,8$ & 1,1 & Volkswagem & $25.900,00$ & 1,1 \\
\hline 30 & Correios & $13.970,4$ & 1,0 & Via Varejo & $25.655,00$ & 1,1 \\
\hline 31 & TAM & $13.695,6$ & 1,0 & $\mathrm{CSN}$ & $25.436,40$ & 1,1 \\
\hline 32 & Claro & $12.916,2$ & 0,9 & Cemig & $25.390,30$ & 1,1 \\
\hline 33 & Globo & $12.710,2$ & 0,9 & Samsung & $24.554,00$ & 1,1 \\
\hline 34 & Usiminas & $12.708,8$ & 0,9 & Cofco & $23.728,40$ & 1,0 \\
\hline 35 & Embraer & $12.201,7$ & 0,9 & Embraer & $21.802,10$ & 0,9 \\
\hline 36 & Neoenergia & $11.810,6$ & 0,8 & Louis Dreyfus & $20.604,40$ & 0,9 \\
\hline 37 & Lojas Americanas & $11.334,1$ & 0,8 & Latam Airlines & $20.363,10$ & 0,9 \\
\hline 38 & Louis Dreyfus & $11.287,1$ & 0,8 & Oi & $20.136,20$ & 0,9 \\
\hline 39 & Sabesp & $10.754,4$ & 0,8 & Energisa & $19.903,10$ & 0,9 \\
\hline 40 & Unilever & $10.108,0$ & 0,7 & Magazine Luiza & $19.886,30$ & 0,9 \\
\hline 41 & Brasiliana Energia & $10.099,8$ & 0,7 & Honda & $19.238,80$ & 0,8 \\
\hline 42 & Toyota & $9.850,5$ & 0,7 & Lojas Americanas & $18.956,30$ & 0,8 \\
\hline 43 & Renault & $9.813,5$ & 0,7 & Equatorial Energia & $18.796,30$ & 0,8 \\
\hline 44 & Mercedes-Benz & $9.686,4$ & 0,7 & Amaggi & $18.793,20$ & 0,8 \\
\hline 45 & Votorantim & $9.481,7$ & 0,7 & Correios & $18.356,10$ & 0,8 \\
\hline 46 & Alesat & $8.952,4$ & 0,6 & Sabesp & $17.983,70$ & 0,8 \\
\hline 47 & Copel & $8.532,2$ & 0,6 & Raia Drograsil & $17.565,60$ & 0,8 \\
\hline 48 & Whirlpool & $8.457,9$ & 0,6 & TIM & $17.377,20$ & 0,8 \\
\hline 49 & Gbarbosa & $8.401,2$ & 0,6 & Minerva Foods & $17.122,80$ & 0,7 \\
\hline 50 & Gol Linhas Aéreas & $8.103,6$ & 0,6 & Copel & $16.244,30$ & 0,7 \\
\hline & Total & $1.397 .262,2$ & 100,0 & Total & $2.314 .764,40$ & 100,0 \\
\hline & ppr. do Agronegócio & $256.154,0$ & 18,3 & Empr. do Agronegócio & $746.223,80$ & 32,2 \\
\hline
\end{tabular}

Fonte: Revista Valor 1.000 Maiores Empresas (VALOR ECONÔMICO, 2021).

Organização: dos autor(a)s

Em termos geográficos, a realização da agricultura científica globalizada está presente sobretudo em áreas de produção e circulação de commodities agrícolas, pois essas regiões recebem maciços investimentos públicos e privados para inserirem produtos nos mercados internacionais de forma competitiva (CASTILLO, 2011). Nessas frações do território evidencia-se a exacerbação da especialização regional e territorial produtiva agrícola, em função do imperativo das exportações e da "commoditização do território", conforme defende Frederico (2013, p. 8):

\footnotetext{
O "imperativo das exportações", resultado da combinação de uma política neoliberal hegemônica com o domínio da lógica financeira na esfera pública e privada, tem estimulado o aumento das exportações de commodities agrícolas, com a exacerbação da especialização regional produtiva do território brasileiro, sobretudo, com produtos agrícolas. Evidencia-se uma "commoditização" não só da economia, mas também do território, uma vez que determinadas regiões passam a atrair investimentos públicos e privados e a reunir uma série
} 
de infraestruturas e normas que as tornam funcionais a uma determinada produção e à lógica do mercado globalizado.

Tal modelo de agricultura está presente, portanto, de forma seletiva no território brasileiro, pois como advertem Santos; Silveira (2001), o meio técnico-científico-informacional está presente em áreas contínuas no Sudeste e no Sul, mas apenas em manchas e pontos no resto do país, em regiões altamente influenciadas pela informação (mercado e ciência) e pelas finanças. Elias (2011, 2013b, 2016, 2017b) destaca que nestas áreas consolidam-se as Regiões Produtivas do Agronegócio (RPAs), cujos traços principais são as intensas relações entre o campo e a cidade e a centralização das operações agroindustriais por grandes empresas. Já Castillo; Frederico (2010), Frederico (2012) e Castillo (2015) propõem que as áreas de maior densidade técnica e normativa para determinados setores e/ou atividade agrícola se constituem em regiões competitivas agrícolas elou agroindustriais (RCAs), conformando modernas espacialidades do capital no agronegócio.

No Mapa 1 é possível visualizar a expansão de algumas das principais culturas no território brasileiro entre 1990 e 2014, atestando-nos que houve a incorporação de largas extensões de áreas para a produção de commodities, acompanhando o movimento da fronteira agrícola moderna, sobretudo de grãos.

A expansão geográfica do agronegócio globalizado sob bases latifundiárias e de monocultivo tem causado, contudo, implicações socioambientais diversas, drástica redução da diversidade produtiva no campo (e também nas pequenas cidades) e forte alienação e dependência dos lugares aos mercados recorrentemente instáveis das commodities agrícolas, revelando um quadro crescente de vulnerabilidade territorial (CASTILLO; FREDERICO, 2010; CAMELINI; CASTILLO, 2012; FREDERICO, 2013; FACCIN; CASTILLO, 2017). Conforme discutem Castillo et al. (2016, p. 271):

\begin{abstract}
As regiões produtivas do agronegócio estão sempre procurando ampliar seus níveis de competitividade, já que disso depende sua existência. Essa busca permanente é também a marca da sua instabilidade e da vulnerabilidade dos municípios (e suas populações) às oscilações dos preços das commodities nos mercados internacionais e às decisões de grandes empresas do agronegócio que, por definição, não têm nenhum compromisso e responsabilidade com os lugares da produção (CASTILLO, 2008; CASTILLO; FREDERICO, 2010). É assim porque o motor da competitividade é a competição na escala internacional.
\end{abstract}

Mapa 1 - Brasil: deslocamento de algumas culturas, 1990-2014 

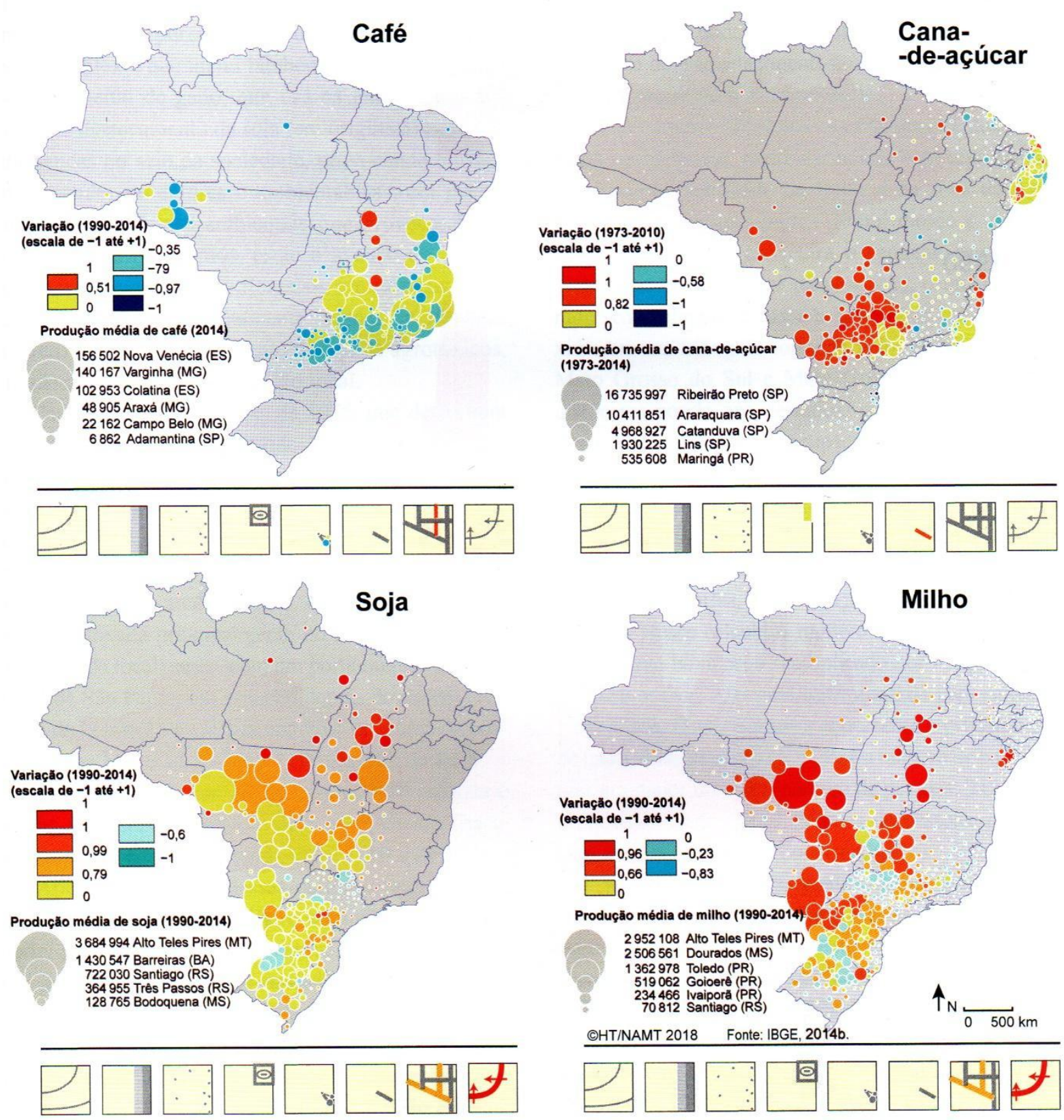

Fonte: Théry; Mello-Théry (2018, p. 165)

Para Brandão (2010), o tipo de competitividade almejada pelos setores produtivos de commodities, por exemplo, que muito dependem da alta produtividade da terra e do trabalho para posicionar regiões e o país nos mercados internacionais, pode representar um quadro de exploração desmedida do território. O fato de as firmas ligadas ao agronegócio, por exemplo, estarem inseridas em um contexto de extrema concorrência internacional por comercialização de produtos que apresentam baixo valor agregado, uniformização técnica e preços únicos estabelecidos em escala global pelas Bolsas de Valor, torna a localização e a possibilidade de 
usarem (ou melhor, explorarem) os recursos e ativos territoriais, em sua máxima condição, decisivas para o alcance da "necessária" competitividade.

Além das repercussões regionais, a vulnerabilidade que se apresenta com a especialização econômica na produção e exportação de commodities também se manifesta na escala do território-nação, já que o Brasil tem dependido cada vez mais dessa atividade para sustentar o seu crescimento econômico. Ao longo das duas primeiras décadas do século XXI observou-se o aumento da participação dos produtos básicos em detrimento dos produtos manufaturados e semimanufaturados no comércio internacional brasileiro, marcando à "reprimarização da pauta exportadora" (LAMOSO, 2020). Além disso, as exportações de commodities agrícolas e minerais são concentradas em poucos produtos e é direcionada, em sua maior parte, para a China, que se tornou o principal parceiro comercial do Brasil, tornando o país extremamente vulnerável às instabilidades comerciais provocadas por intercorrências econômicas, políticas e diplomáticas daquele país. Há inclusive alguns autores (CANO, 2012; ESPÓSITO, 2017) que defendem a ideia de que o Brasil, em função desse perfil exportador e da falta de uma política industrial mais consistente, estaria passando por um processo de "desindustrialização", o que tem diminuído o nível de diversificação das fontes de divisas e reforçado a nossa dependência econômica em relação ao agronegócio.

\section{CONSIDERAÇÕES FINAIS}

Em suma, apreendemos com base nos recentes estudos da Geografia (BURCH; LAWRENCE, 2009; CASTILLO, 2011; FREDERICO, 2013; STEDILE, 2013; WOLF; BONANNO, 2014; OLIVEIRA, 2016; ELIAS, 2013a; 2017a; IORIS, 2018a, 2018b) que o paradigma do agronegócio globalizado conforma-se nas seguintes características: i) difusão das Novas Tecnologias de Informação e da Comunicação (NTICs) nas etapas da produção e logística; ii) política estatal de viés neoliberal na economia agropecuária; iii) internacionalização dos circuitos espaciais produtivos e círculos de cooperação agrícolas e/ou agroindustriais; iv) hegemonia do capital financeiro (mercado futuro de commodities, creditização da produção, derivativos, formas de remuneração dos acionistas, Land Grabbing) nas decisões e estratégias corporativas de grandes empresas do agronegócio; v) concentração e centralização do capital nos vários segmentos do agronegócio (insumos químicos, biológicos, maquinários, produção e processamento de matéria-prima, distribuição e comercialização), implicando em oligopolização da produção e comercialização; vi) especialização regional e territorial produtiva de commodities agrícolas.

A consolidação do agronegócio globalizado sob fundamentos econômicos e políticos do Neoliberalismo é um dos principais eventos que vem reestruturando o território brasileiro, significando diversas implicações espaciais. As atividades agropecuárias estão, mais do que nunca, subordinadas a uma dinâmica dos mercados globais que se sustentam pelos mecanismos de acumulação das grandes corporações e do capital financeiro, estes, cada vez mais, influenciando e centralizando poderosamente as decisões nas esferas política, produtiva, 
logística, comercial e no consumo de matérias-primas e bens industrializados. É por meio da busca pela valorização de ativos tangíveis (terras, bens de capital e de produção, mercadorias etc.) e intangíveis (estratégias corporativas, estoque de conhecimentos, inovações tecnológicas etc.), muitas vezes a todo custo social e ambiental, que os agentes dominantes (grandes empresas nacionais e transnacionais, latifundiários, especuladores financeiros) se organizam, usam corporativamente o território e garantem a constituição de estruturas monopólicas no mercado.

As implicações socioespaciais desse padrão de produção agropecuária moderno e expropriador são várias: i) descapitalização dos pequenos produtores e camponeses e sua inviabilidade produtiva dentro do novo padrão agrícola; ii) redução da capacidade desse grupo social em competir no mercado institucional, em termos de qualidade e custos; iii) sujeição produtiva (relação custo e preço de comercialização) daqueles que continuaram produzindo, ao capital industrial (agroquímicos, maquinários, sementes e mudas, agroindústria) e ao capital financeiro (empréstimos a juros altos, dependência em relação à cotação internacional de commodities); iv) proletarização e precarização (em termos de rendimento do trabalho versus salário) das populações rurais; v) aumento do êxodo rural em função da inviabilidade produtiva de parte da classe campesina e da mecanização massiva das operações agrícolas; vi) aumento da concentração fundiária e da violência do campo, com expulsão de posseiros e populações tradicionais (indígenas, quilombolas, ribeirinhas, etc.); vii) degradação ambiental via contaminação de solos, águas e queimadas, entre outras (PALMEIRA, 1989; MARTINS, 1991; STEDILE, 2013; OLIVEIRA, 2011; 2015a; 2016; ELIAS, 2021b).

Portanto, para construirmos um novo projeto de nação com menos desigualdades, urge-se a realização de uma reforma agrária efetiva no Brasil, que contemple uma ampla distribuição de terras aos mais pobres e uma política nacional que priorize o efetivo desenvolvimento social, a capacidade produtiva e a dignidade das pessoas que ainda permanecem no campo. Além das políticas conjuntas de habitação, saúde, educação e infraestrutura rural, várias outras ações estatais poderiam contribuir para esse desafio, tais como: aprimorar o sistema de delimitação e regularização de terras; incentivar a criação e dar suporte à uma rede de associações e cooperativas de fortalecimento à agricultura familiar; desburocratizar os processos de contratação de crédito rural e aumentar os recursos aos pequenos produtores; ampliar e aperfeiçoar os programas de assistência técnica e extensão rural para os pequenos; ofertar a contratação de máquinas e equipamentos agrícolas pelos pequenos agricultores a preços baixos; criar mecanismos de garantia de competitividade da agricultura familiar no mercado agrícola, via preços mínimos, estímulos a nichos de mercado específicos (agroecologia, alimentos orgânicos, etc.) e disponibilização de infraestruturas (veículos, estradas em boas condições, armazéns públicos) para a logística de produtos agropecuários.

\section{AGRADECIMENTOS}




\section{Agradeço a Fundação de Amparo à Pesquisa do Estado de São Paulo (FAPESP) pela bolsa concedida para a execução desta pesquisa.}

\section{NOTAS}

1 - Segundo Pires; Ramos (2009), o termo modernização conservadora remete a ideia discutida por vários teóricos, sobretudo Alberto Passos Guimarães, Fernando Antônio Azevedo, Ignácio Rangel, Florestan Fernandes, Caio Prado Júnior, Graziano da Silva, Guilherme Delgado e Maria da Conceição Tavares; de que o processo de modernização da agricultura brasileira baseou-se no progresso técnico-produtivo do campo sem, contudo, ocorrer o fracionamento da estrutura fundiária nacional. Os autores pontuam, baseado nesses teóricos, que além desse, outros aspectos estão associados ao termo, em suas causas e consequências, como: a estratégia de domínio do poder político da elite aristocrata sobre as outras classes sociais por meio da segregação econômico-financeira (discriminação no acesso a crédito e a terras); a sujeição mercadológica dos produtores rurais ao consumo de inovações mecânicas, físico-químicas e biológicas; a aceleração do êxodo rural; e o descompasso de trabalhadores livres com a oferta de colocações no mercado de trabalho. Assim, "o processo de modernização conservadora da agropecuária nacional foi marcado por uma exclusão autoritária das classes sociais do acesso aos mercados de dinheiro, trabalho e terras" (PIRES; RAMOS, 2009, p. 419).

2 - Segundo Castillo (2011, p. 340), "por commodity entendemos um produto primário ou semielaborado, mineral ou agrícola, padronizado mundialmente, cujo preço é cotado nos mercados internacionais, em bolsas de mercadorias. Trata-se de uma invenção não apenas econômico-financeira, mas também política, que enfraquece e submete o produtor local - pelo menos quando se trata de commodity agrícola - a uma lógica única ou global e a uma situação sobre a qual não se exerce nenhum controle, favorecendo os compradores ou as grandes empresas de comercialização (tradings). A lógica das commodities opõe agentes atrelados ao lugar ou à região aos agentes que atuam em rede".

3 - O termo "Complexo Agroindustrial" é utilizado por vários autores, como Guimarães (1975), Delgado (1985), Muller (1989), Kageyama et al. (1990) e Graziano da Silva (1998), para explicar a nova dinâmica da agricultura brasileira que desponta a partir da década de 1960, pautada na intensa subordinação e/ou integração da agricultura à indústria e a outros setores da economia de forma geral. De acordo com Muller (1989, p. 45), podemos entender o Complexo Agroindustrial como "o conjunto formado pela sucessão de atividades vinculadas à produção e transformação de produtos agropecuários e florestais. Atividades tais como: a geração destes produtos, seu beneficiamento/transformação e a produção de bens de capital e de insumos industriais para atividades agrícolas; ainda: a coleta, a armazenagem, o transporte, a distribuição dos produtos industriais e agrícolas; e ainda mais: o financiamento, a pesquisa e a tecnologia, e a assistência técnica".

4 - De acordo com Gonçalves Neto (1996, p. 174), em 1966 os pequenos produtores eram responsáveis por 43\% de toda aquisição do crédito rural para a agricultura, caindo para $11 \% \mathrm{em} \mathrm{1976,} \mathrm{enquanto} \mathrm{os} \mathrm{grandes} \mathrm{produtores}$ tiveram aumento de $20 \%$ para $53,5 \%$ na participação dos recursos, no mesmo período. Processo semelhante ocorreu com o crédito rural para a pecuária: a participação dos pequenos produtores caiu de $33 \%$ para $12 \%$, enquanto a dos grandes produtores aumentou de $12 \%$ para quase $47 \%$.

5 - Segundo Mazzali (2000), as NTICs provocaram profunda reorganização das formas de produção, logística, comercialização e do relacionamento entre agentes (empresas, Estado, consumidores, instituições financeiras e PD\&I etc.), tornando mais flexíveis as várias etapas de produção e circulação de produtos conforme demandas e ofertas do mercado. Também contribuíram para o aumento das possibilidades de padronização, diversificação de produtos e processos, agregação de valor, ganho de tempo e redução de custos.

6 - Exemplos desses agentes são as tradings Bunge, Cargill, Archer Daniels Midland (ADM), Louis Dreyfus Company (LDC) e Cofco. 
7 - De acordo com Mazzali (2000), a partir de Guillon (1992), as redes verticais são organizadas em torno de uma empresa principal (uma holding, por exemplo) e seus diversos agentes complementares (produtores, fornecedores, distribuidores etc.) dotados de competências técnicas específicas dentro de cada cadeia produtiva. Já as redes horizontais se formam a partir das alianças ou cooperações estratégicas entre corporações concorrentes (inclusive de cadeias produtivas diferentes), objetivando assegurar acesso a novos conhecimentos e/ou a entrada em novos mercados, aproveitando economias de escala e escopo.

\section{REFERÊNCIAS}

ARACRI, Luís A. Reestruturação produtiva, território e difusão de inovações no campo: a agricultura de precisão em Mato Grosso. Rio de Janeiro: Arquimedes, 2012.

BALESTRO, Moisés V.; LOURENÇO, Luiz C. de B. Notas para uma análise da financeirização do agronegócio: além da volatilidade dos preços das commodities. In: BUAINAIN, Antônio M. et al. O mundo rural no Brasil do século 21: a formação de um novo padrão agrário e agrícola. Brasília/DF: Embrapa, 2014, p. 241-265.

BERNARDES, Júlia. A. et al. Globalização do agronegócio e land grabbing: a atuação das megaempresas argentinas no Brasil. Rio de Janeiro: Lamparina, 2017.

BERNARDES, Júlia A. Novas fronteiras do capital no Cerrado: dinâmica e contradições da expansão do agronegócio na região Centro-Oeste, Brasil. Scripta Nova, v. XIX, n. 507, 2015.

BRANDÃO, Carlos. Acumulação primitiva permanente e desenvolvimento capitalista no Brasil contemporâneo. In. ALMEIDA, A. W. B. de et al. Capitalismo globalizado e recursos territoriais. Rio de Janeiro: Lamparina, 2010, p. 39-70.

BRENNER, Neil.; PECK, Jamie.; THEODORE, Nik. Towards Deep Neoliberalization? In: KUNKEL, Jenny.; MAYER, Margit. (eds) Neoliberal Urbanism and its Contestations. London: Palgrave Macmillan, 2012.

BRUNHOFF, Suzanne. et al. A Finança Capitalista. Trad. Rosa Maria Marques e Paulo Nakatani. São Paulo: Alameda, 2010.

BuAINAIn, Antônio M; BONACELli, Maria B. M.; MENDES, Cássia I. C. Propriedade Intelectual e Inovações na Agricultura. Brasília; Rio de Janeiro: CNPq, FAPERJ, INCT/PPED, IdeiD, 2015.

BUAINAIN, Antônio. M. et al. O mundo rural no Brasil do século 21: a formação de um novo padrão agrário e agrícola. Brasília/DF: Embrapa, 2014.

BURCH, David.; LAWRENCE, Geoffrey. Towards a third food regime: behind the transformation. Agriculture and Human Values, v. 26, p. 267-279, 2009.

CAMELINI, João. H.; CASTILLO, Ricardo. Etanol e Uso Corporativo do Território. Mercator, v. 11, n. 25, p. 7-18, mai./ago. 2012.

CANO, Wilson. A desindustrialização no Brasil. Economia e Sociedade, v. 21, p. 831-851, 2012.

CASTILLO, Ricardo. Agricultura globalizada e logística nos cerrados brasileiros. In: SILVEIRA, M. R. (org.). Circulação, transportes e logística: diferentes perspectivas. São Paulo: Outras Expressões, 2011, p. 331-354. 
CASTILLO, Ricardo. Região competitiva e logística: expressões geográficas da produção e da circulação no período histórico atual. In: IV SEMINÁRIO INTERNACIONAL SOBRE DESENVOLVIMENTO REGIONAL. (Anais). Santa Cruz do Sul (RS): Unisc, 2008.

CASTILlO, Ricardo. Agronegócio e Logística em Áreas de Cerrado: expressão da agricultura científica globalizada. Revista da Anpege, v. 3, p. 33-43, 2007.

CASTILlO, Ricardo.; ELIAS, Denise.; PEIXINHO, Dimas.; BUHLER, Eve.; PEQUENO, Renato. Regiões do agronegócio, novas relações campo-cidade e reestruturação urbana. Revista da Anpege, v. 12, n. 18, p. 265-288, 2016.

CASTILlO, Ricardo; FREDERICO, Samuel. Dinâmica regional e globalização: espaços competitivos agrícolas no território brasileiro. Mercator - Revista de Geografia da UFC, v. 9, n. 18, p. 17-26, jan./abr. 2010.

CHENG, Ing-Haw.; XIONG, Wei. The financialization of Commodity Markets. Working Paper. Massachusetts: National Bureau of Economic Research, 2013.

CHESNAIS, François. (Org.) A finança mundializada. São Paulo: Boitempo, 2005.

CLAPP, Jennifer. Financialization, distance and global food politics. The Journal of Peasant Studies, v. 41, n. 5, p. 797-814, 2014.

CLAPP, Jennifer.; ISAKSON, Ryan.; VISSER, Oane. The complex dynamics of agriculture as a financial asset: introduction to symposium. Agriculture and Human Values, v. 34, p. 179-183, 2017.

DARDOT, Pierre.; LAVAL, Christian. A nova razão do mundo: ensaio sobre a sociedade neoliberal. Trad. Mariana Echalar. São Paulo: Boitempo, 2016.

DELGADO, Guilherme. C. Do capital financeiro na agricultura à economia do agronegócio: mudanças cíclicas em meio século (1965-2012). Porto Alegre: Editora da UFRGS, 2012.

DELGADO, Guilherme. C. Capital financeiro e agricultura no Brasil 1965-1985. Campinas: Ícone Editora/Editora Unicamp, 1985.

ELIAS, Denise. O alimento-mercadoria e a forme no Brasil. Boletim Goiano de Geografia, v. 41, 2021a.

ELIAS, Denise. Mitos e nós do agronegócio no Brasil. Geousp, v. 25, n. 2, p. 1-18, 2021 b.

ELIAS, Denise. Agronegócio globalizado e (re)estruturação urbano-regional. In: ENCONTRO NACIONAL DA ANPUR (ENANPUR). Anais. São Paulo: USP, 2017a.

ELIAS, Denise. Construindo a noção de Região Produtiva do Agronegócio. In: OLIVEIRA, H. C. M. de; CALIXTO, M. J. M. S.; SOARES, B. R. (Orgs.). Cidades médias e região. São Paulo: Cultura Acadêmica, 2017b, p. 19-55.

ELIAS, Denise. Agronegócio e reestruturação urbana e regional no Brasil. In: BUHLER, E. A.; GUIBERT, M.; OLIVEIRA, V. L. (Orgs.) Agriculturas empresariais e espaços rurais na globalização. Porto Alegre: Editora da UFRGS, 2016, p. 63-81.

ELIAS, Denise. Globalização, Agricultura e Urbanização no Brasil. Revista ACTA Geográfica (edição esp. Geografia Agrária). Boa Vista, p. 13-32, 2013 a.

ELIAS, Denise. Regiões produtivas do agronegócio: notas teóricas e metodológicas. In: BERNARDES, J. A., SILVA, C. A., ARRUZZO, R. C. (Orgs.) Espaço e energia: mudanças no paradigma sucroenergético. Rio de Janeiro: Lamparina, 2013b, p. 201-220. 
ELIAS, Denise. Agronegócio e Novas Regionalizações no Brasil. Revista Brasileira de Estudos Urbanos e Regionais, v. 13, n. 2, p. 153-167, nov. 2011.

ELIAS, Denise. O Brasil agrícola com áreas urbanas: a cidade do agronegócio. In: OLIVERIA, J. A. (Org.). Cidades Brasileiras: territorialidades, sustentabilidade e demandas sociais. Manaus: UFAM, 2010, p. 147-164.

ELIAS, Denise. O meio técnico-científico-informacional e a reorganização do espaço agrário nacional. In: MARAFON, G. J.; RUA, J.; RIBEIRO, M. (orgs.) A. Abordagens teórico-metodológicas em geografia agrária. Rio de Janeiro: Ed. UERJ, 2007a, p. 49-66.

ELIAS, Denise. Agricultura científica no Brasil: impactos territoriais e sociais. In: SOUZA, M. A. A. de (org.). Território brasileiro: usos e abusos. Campinas: Territorial p. 315-340, 2003.

ESPÓSITO, Maurício. Desindustrialização no Brasil: uma análise a partir da perspectiva da formação nacional. Revista da Sociedade Brasileira de Economia Política, v. 46, p. 120-146, 2017.

FACCIN, Ana. C. T. M.; CASTILLO, Ricardo. A. Vulnerabilidade territorial e implicações sócio-espaciais da expansão do complexo soja no Mato Grosso do Sul. Estudos Geográficos, v. 15, n. 1, p. 133-156, jan./jun. 2017.

FREDERICO, Samuel. Agricultura científica globalizada e fronteira agrícola moderna no Brasil. Revista Confins. Paris, vol. 17, p. 1-17, 2013.

FREDERICO, Samuel. Imperativo das exportações e especialização agrícola do território brasileiro: das regiões competitivas à necessidade de regiões cooperativas. Geografia, Rio Claro, v. 37, n. 1, p. 5-18, jan./abr. 2012.

FREDERICO, Samuel. O Novo Tempo do Cerrado: expansão dos fronts agrícolas e controle do sistema de armazenamento de grãos. São Paulo: Annablume; FAPESP, 2010.

GONÇALVES NETO, W. Estado e Agricultura no Brasil: política agrícola e modernização econômica 1960-1980. São Paulo: Hucitec, 1997.

GRAZIANO DA SILVA, José. A nova dinâmica da agricultura brasileira. $2^{\circ}$ ed. São Paulo: UNICAMP, 1998.

GUIMARÃES, A. P. A crise agrária. Rio de Janeiro: Paz e Terra. 1979.

HARVEY, David. (2005). O Neoliberalismo: história e implicações. Trad. Adail Ubirajara Sobral, Maria Stela Gonçalves. 2 ed. São Paulo: Edições Loyola, 2011.

HESPANHOL, Antônio. N. Agricultura, desenvolvimento e sustentabilidade. In: MARAFON, G. J.; RUA, J.; RIBEIRO, M. (orgs.) A. Abordagens teórico-metodológicas em geografia agrária. Rio de Janeiro: Ed. UERJ, 2007, p. 179-198.

IORIS, Antônio. A. R. Agribusiness and the Neoliberal Food System in Brazil: frontiers and fissures of Agro-neoliberalism. New York: Routledge, 2018a.

IORIS, Antônio. A. R. The Politics of Agribusiness and the Business of Sustainability. Sustainability, v. $10,2018 \mathrm{~b}$.

IORIS, Antônio. A. R. Seeding a narrow future and harvesting an exclusionary past: The contradictions and future scenarios of agro-neoliberalism in Brazil. Futures, v. 95, p. 76-85, 2018b.

IORIS, Antônio. A. R. The politico-ecological economy of neoliberal agribusiness: displacement, financialization and mystification. Area, v. 48, n. 1, p. 84-91, 2016. 
ISAKSON, Ryan. S. Food and finance: the financial transformation of agro-food supply chains. The Journal of Peasant Studies, v. 41, n. 5, p. 749-775, 2014.

KAGEYAMA, Angela. et al. (org.). O Novo Padrão Agrícola Brasileiro: do Complexo Rural aos CAIs. In: DELGADO, Guilherme. et al. (org.). Agricultura e políticas públicas. IPEA, 1990, p. 113-223.

KATO, Karina; LEITE, Sergio. Land grabbing, financeirização da agricultura e mercado de terras: velhas e novas dimensões da questão agrária no Brasil. Revista Anpege, v. 6 n. 29, p. 452-483, 2020.

LAMOSO, Lisandra. Reprimarização no território brasileiro. Espaço e Economia: revista brasileira de Geografia Econômica, n. 19, 2020.

MATOS, Paula. F.; PESSÔA, Vera. L. S. A Modernização da agricultura no Brasil e os novos usos do território. Revista Geo UERJ. Rio de Janeiro: UERJ, n. 22, vol. 2, jul.-dez/2011, p. 290-322.

MARTIN, Sarah.; CLAPP, Jennifer. Finance for Agriculture or Agriculture for Finance? Journal of Agrarian Change. V. 15, n. 4, p. 549-559, 2015.

MARTINS, José. de S. Expropriação e violência: a questão política no campo. São Paulo: Hucitec, 1991.

MASSRUHÁ, S. M. F. S. et al (Ed. Téc.) Tecnologia da informação e comunicação e suas relações com a agricultura. Brasília, DF: Embrapa, 2014.

MAZZALI, Leonel. O processo recente de reorganização agroindustrial: do complexo à organização "em rede". São Paulo: Editora Unesp, 2000.

MCGILL, Sarah. The Financialization Thesis Revisited: Commodities as an Asset Class. In: CLARK, G. L. et al. The New Oxford Handbook of Economic Geography. Oxford, 2018.

MULLER, Geraldo. Complexo agroindustrial e modernização agrária. São Paulo: HUCITEC, 1989.

OLIVEIRA, Ariovaldo. U. A Mundialização da Agricultura Brasileira. São Paulo: Iãnde Editorial, 2016.

OLIVEIRA, Ariovaldo. U. A Mundialização do capital e a crise do neoliberalismo: o lugar mundial da agricultura brasileira. Revista GEOUSP: espaço e tempo, v. 19, n. 2, p. 228-244, 2015.

PALMEIRA, Marcos. Modernização, Estado e questão agrária. Estudos Avançados, v. 3, n. 7, 1989 , p. $87-108$.

PAULA, Nilson. M.; SANTOS, Valéria. F.; PEREIRA, Wellington. S. A financeirização das commodities agrícolas e o sistema agroalimentar. Estudos Sociedade e Agricultura, v. 23, n. 2, p. 294-314, 2015.

PIRES, Murilo. J. S.; RAMOS, Pedro. O termo modernização conservadora: sua origem e utilização no Brasil. Revista Econômica do Nordeste, v. 40, n. 3, jul.-set., 2009, p. 411-424.

SAES, Maria. S. M.; SILVEIRA, Rodrigo. L. F. Novas formas de organização das cadeias agrícolas brasileiras: tendências recentes. In: BUAINAIN, Antônio. M. et al. O mundo rural no Brasil do século 21: a formação de um novo padrão agrário e agrícola. Brasília/DF: Embrapa, 2014, p. 298-315.

SANTOS, Milton. (2000) Por uma outra globalização: do pensamento único à consciência universal. 19 ed. Rio de Janeiro: Record, 2010. 
SANTOS, Milton. (1996) A natureza do Espaço. Técnica e tempo. Razão e emoção. 4 ed. São Paulo: Edusp, 2012.

SANTOS, Milton. (1994) Técnica, espaço, tempo: globalização e meio técnico-científico informacional. 5 ed. São Paulo: HUCITEC, 2008.

SANTOS, Milton.; SILVEIRA, Maria. L. (2001) O Brasil: território e sociedade no início do século XXI. $13^{\circ}$ ed. São Paulo: Record, 2010.

SILVEIRA, José. M. da. Agricultura brasileira: o papel da inovação tecnológica. In: BUAINAIN, A. M. et al. O mundo rural no Brasil do século 21: a formação de um novo padrão agrário e agrícola. Brasília/DF: Embrapa, 2014, p. 374-394.

STEDILE, João Pedro (Org.). A Questão Agrária no Brasil: o debate na década de 2000. São Paulo: Expressão Popular, 2013.

THÉRY, Hervé; MELLO-THÉRY, Neli A. Atlas do Brasil: Disparidades e Dinâmicas do Território. $3^{\circ}$ ed. São Paulo: EDUSP, 2018.

VALOR ECONÔMICO. Revista Valor 1000 Maiores Empresas. Disponível em: https://especial.valor.com.br/valor1000. Acesso em: out./2021.

VIEIRA FILHO, José. E. R. Transformação histórica e padrões tecnológicos da agricultura brasileira. In: BUAINAIN, A. M. et al. O mundo rural no Brasil do século 21: a formação de um novo padrão agrário e agrícola. Brasília/DF: Embrapa, 2014, p. 396-421.

ZYLBERSZTAJN, Decio. Coordenação e governança de sistemas agroindustriais. In: BUAINAIN, A. M. et al. O mundo rural no Brasil do século 21: a formação de um novo padrão agrário e agrícola. Brasília/DF: Embrapa, 2014, p. 268-294.

ZYLBERSZTAJN, Decio.; NEVES, Marcos. F. (Orgs.) Economia e Gestão dos Negócios Agroalimentares. São Paulo: Pioneira, 2000.

WOLF, Steven. A.; BONANNO, Alessandro. The Neoliberal Regime in the Agri-Food Sector: crisis, resilience, and restructuring. New York: Routledge, 2014.

\section{COMO CITAR ESTE TRABALHO}

SANTOS, Henrique Faria dos. Neoliberalismo e expansão do agronegócio globalizado no Brasil. Revista Tamoios, São Gonçalo, v. 18, n. 1, p. 21-46, 2022. Disponível em: https://doi.org/10.12957/tamoios.2022.63310. Acesso em: DD MMM. AAAA. 